\title{
The Ebb and Flow of Identity Formation and Competence Development in Sub-specialty Residents: Study of a Continuity Training Setting
}

Noureen Huda ( $\square$ noureen.huda@lhsc.on.ca )

Western University https://orcid.org/0000-0002-3768-6849

\section{Lisa Faden}

Western University

Claire A. Wilson

Western University

Rachel A. Plouffe

Western University

Edmond Li

Imperial College London

Manpreet Kaur Saini

University of Limerick

\section{Saad Chahine}

Queens University

\section{Research article}

Keywords: Professional identity, competence based education, continuity training, grounded theory

Posted Date: May 1st, 2020

DOl: https://doi.org/10.21203/rs.3.rs-24203/v1

License: (9) (i) This work is licensed under a Creative Commons Attribution 4.0 International License.

Read Full License 


\section{Abstract \\ Background}

Professional identity and competence development are evolving processes, shaped by clinical experiences and socialization in the workplace. The purpose of this study was to investigate the simultaneous development of professional identify formation and competence in a sub-specialty training program.

\section{Methods}

The study was conducted in a General Internal Medicine sub-specialty (PGY-4 and PGY-5) continuity training setting, at an academic health sciences center, in Canada. Participants included: current residents, recent graduates, attending physicians and administrative assistants. Data was collected from 2017-2018. A constructivist grounded theory approach was used to analyze anonymized focus group and individual interviews.

\section{Results}

The study identified the following: 1) learning activities that support professional identity formation in advanced residents; 2 ) the relationship between professional identity formation and competencies; 3 ) the role of administrative assistants and continuity training supervisors in supporting professional identity formation; and 4) a set of invisible learning experiences that occurred as a result of assumptions made by residents about expectations of training and expectations of patient care. Although, there was limited data available on the latter, findings suggested that invisible learning experiences may adversely impact residents' functioning as independent physicians.

\section{Conclusions}

Residents' professional identities continue to evolve with increasing competency requirements during training. Training programs, for sub-specialty residents, must balance granting of independence with supporting ongoing professional identity formation. They must also be explicit about what constitutes healthy patient care expectations and how practicing physicians manage these expectations.

\section{Background}

Studies on Professional Identity Formation (PIF) have predominantly focused on medical students[1-8] and residents in core training programs [9-11], and have overlooked the evolving identity formation of more advanced residents in sub-specialty training programs. Recent literature recognizes that PIF is an ongoing process that evolves with varying professional experiences, beyond residency training, and may 
take on different trajectories for physicians $[12,13]$. Yet, to date, little attention has been given to how PIF evolves with advanced sub-specialty training, as well as how PIF can be supported in the developmental trajectory of residents, and how competency acquisition parallels with PIF. Thus the purpose of this study was to provide one of the first investigations of PIF and competence development in a sub-specialty training program.

PIF is supported by socialization in the workplace [14]; continuity of clinical experience [6]; and reflective practice $[2,5,15,16]$. Socialization involves interactions with patients, caregivers, clinical supervisors and other healthcare members $[3,15,17]$.These interactions foster therapeutic relationships and create meaningful learning experiences that help students appreciate their role as physicians [3].Continuity training supports apprenticeship models where students can build trusting relationships with supervisors and feel safe in discussing concerns around their learning and development [6]. For the supervisor, continuity training settings allow them to closely observe the struggling students and observe transformations in their professional identity [6]. Supervisor led reflective practice facilitates selfawareness and mindfulness in the development of physicians $[16,18]$ and thus, makes the student an active participant in their own transformation [18].

While socialization, mentorship and reflection are a deliberate and more structured part of curriculum for medical students $[2,4,5,9,15,17]$, more advanced trainees, in sub-specialty programs must be granted independence as an expectation of training. This limits the ability to integrate reflective practice and mentorship as a formal part of their training. As recent studies point to PIF as an ongoing process in physicians $[12,13,20-22]$, it is pertinent to understand how PIF support can be balanced with gradual independence in advanced trainees. The balance of supervision and gradual independence has become even more critical with Competency Based Medical Education (CBME) [23, 24]. With CBME, advocates of PIF are also urging on the need to integrate identity formation with discipline-specific competencies $[25$, 26]. Specifically, they draw attention to advanced residents whose competencies have likely solidified during earlier years in training, but now, their ongoing professional development is around "being a physician" [25]. This development into a holistic physician, who is not only competent, but also identifies as a physician occurs through more complex, yet meaningfully integrated, experiences in the workplace [26]. By assessing the identity formation [27] concurrently with competencies, would allow programs to move from assessment of individual competencies, towards assessment of the whole physician $[28,29]$.

Presently, much of the PIF literature still focuses on improving curriculum and other interventions for medical students and residents in core training programs [9-11, 26]. As sub-specialty residents are developmentally more advanced, have more complex levels of competency to achieve, and are expected to work more independently, programs need to understand how to support their developmental trajectory. Hence, the questions for this study were: 1) how do competencies and PIF develop simultaneously for advanced residents and 2) what is the relationship between specialty specific competencies and PIF.

\section{Methods}




\section{Setting}

This study was conducted from April 2017-March 2018. The study included four out-patient General Internal Medicine (GIM) continuity training sites, at an academic health sciences center in London, Canada. GIM in Canada is a two-year sub-specialty training program, consisting of postgraduate $4^{\text {th }}$ and $5^{\text {th }}$ year residents (PGY-4 and PGY-5 respectively), who have successfully completed three years of Internal Medicine training.

Each site has 2-3 continuity training clinics. Each clinic team consists of a continuity resident, an attending physician and an administrative assistant to the physician. The resident's patient care responsibilities include: providing consultations on new patients; seeing their follow up patients; following up on their patients' test results and communicating with the patient's primary care provider. The resident's administrative responsibilities include working with the administrative assistant to triage new referrals, book follow ups and responding to their patient's concerns after the clinic. The attending physician is responsible for overseeing the resident's performance, for reviewing the cases in clinic, and for mentorship across all aspects of out-patient care. The administrative assistant is responsible for organizing the continuity clinic; notifying the resident about test results that have arrived and about any patients calling in with concerns. If the resident is unresponsive to the administrative assistant, the assistant will notify the physician.

\section{Participants}

The study included 18 participants (8 administrative assistants, 4 residents, 3 graduates and 3 continuity clinic attending physicians). All three attending physicians had four years of experience in supervising continuity clinic residents in this setting. Of the eight administrative assistants, five had four years of experience supervising continuity clinic residents and the rest had one to two years of experience. The graduates were within 1-2 years of graduation and include both community and academic general internists.

All participants consented to audio-recorded interviews and transcripts were anonymized.

\section{Methods}

We drew on Grounded Theory methods $(31,32)$ to facilitate data collection and analysis of the processes associated with continuity training. Iterative data analysis was used to refine interview questions during data collection. Purposeful sampling was used to select participants who would offer rich insights into the training process and into factors that influenced personal growth as physicians. For this reason, our trainee sample includes only PGY-5 residents and graduates. Sensitizing concepts from PIF [14] were used to facilitate interpretation and analysis of interview data. The data was also analyzed for the key GIM competencies as outlined in the training documents from the Royal College of Physicians and Surgeons of Ontario [33]. Specifically, we analyzed data for the following documented competencies: 
caring for multi-morbid patients; investigating for undifferentiated multi-system symptoms; managing a GIM practice independently; and developing life-long learning skills.

NVivo11 software (QSR, Melbourne,Australia) was used for data storage and analysis. Preliminary coding was developed by the research assistants: CW, RP, EL and MS. After achieving consensus, preliminary codes were grouped into themes associated with PIF. The themes were then further explored in the data and in subsequent interviews. Findings from the graduate and resident interviews informed data collection in the administrative assistant and attending physician interviews. Final coding for achieving consensus and refining discrepant codes were reviewed by NH, LF and SC. Memos and audit trails were maintained to add rigour to the analysis.

In addition, to support the analytic process, all team members weighed in on the knowledge construction. The preliminary findings were shared with colleagues in GIM and colleagues with expertise in competency based education and professional identity.

\section{Results}

The results were centered around three main themes: the activities that support PIF; the relationship between PIF and General Internal Medicine (GIM) competencies and the invisible learning experiences that were not an explicit part of training.

\section{Activities that Support PIF}

In continuity clinics, residents participate in various learning activities with their attending physicians and outside of the clinics with the administrative assistants. In addition to this, they interact with patients in clinics and after the clinical encounter. These activities collectively shape their PIF by helping them to recognize the concept of patient ownership; develop strategies to balance patient care and their own learning needs; and understand how a GIM practice functions: [Continuity clinic] was a crucial component of my training. It helps you navigate the [healthcare] system better. You start to get [patient] information to your office from other providers; patients have needs. So, you're met with a lot of challenges doing this, [and] you have to create solutions during the process (Graduate1). For the data analysis, we divided these into three key activities that are tangible from the learners' perspective: 1 . the roles of attending physicians, 2. administrative assistants and 3. patients with multi-morbidity.

\section{Attending Physicians}

Attending physicians placed a greater emphasis on coaching, modelling and mentorship when residents first started continuity training. As internal medicine residents, a majority of the residents' experience has been on ambulatory clinics in block rotations. As a result, they are not prepared for the full extent of continuity care required for GIM patients. As residents developed skills and acquired the competencies for caring for GIM patients, attending physicians granted them more independence. 
Attending physicians coached on how to track test results after the clinic; how to communicate the results over the phone; and how to manage the patient's response and follow up questions. This fostered a sense of patient ownership in the residents. Coaching also supported other competencies such as: resource management "not all tests have to be done in the first visit" (AP1) and patient advocacy "I show them how I learned to organize IV infusions as an out-patient" (AP2).

In our study, mentorship throughout training was necessary in guiding the PIF of residents. Specifically, attending physicians stressed the need to "treat each patient encounter as a learning opportunity, instead of just getting through the clinic work' (AP1). This not only advanced their knowledge base but also built confidence and the ability to "think like an internist" (AP1). In addition to this mentorship was key in learning how to create time, between competing clinical demands, to communicate with the patient about their concerns.

However, there were some continuity training activities that required more explicit modelling. For example, communicating with patients around behavior change or goals of care related to their chronic illnesses, "I'm overt about sitting down with a patient to say, look, what are you actually hoping is going to happen with your care, and get into that goals of care discussion in a deep and rich enough way to open up a door for change. Because for many of our patients it's a chronic active, medical illness and [these] play a role. This helps the resident recognize when you have to go deep, knowing the right moments for it and then prompting it in the right places" (AP3).

Ultimately, attending physicians set high expectations that the residents would assume full ownership of patient care in clinic and they strategized around this, "I set up structures that enforce [ownership] rather than me owning it" (AP1). As residents progressed and began demonstrating greater independence, attending physicians scaled back on their supervisory role, but made themselves available for second opinions, "as their knowledge and confidence increases, we start working more like colleagues" (AP2).

\section{Administrative Assistants}

Administrative assistants were well-positioned to observe residents' non-clinical skills that are necessary for practice management; to provide support with navigating the healthcare system; and to provide feedback to the Attending Physician on residents' professional development. Residents had to work with administrative assistants to triage patients, book follow-ups, arrange for investigations and receive communications from their patients. In turn, administrative assistants relied on the residents to update them about their other training commitments, such as, on-call, other rotations or academic requirements that conflicted with the continuity clinic.

Since administrative assistants worked closely with the residents, they were able to observe how professional behaviors evolved over time. Behaviors that were felt to be critical for practice management were communication style: 
" when they first start everything is a question; then they become more confident, they speak up more and it's no longer a question but a decision" (AA6)

responsibility towards patients:

"I don't take [patient issues] to the consultant. I take it to the resident and make them responsible for their patient. I let them make the decision and if they have a question, they can address it with the consultant" (AA4)

and responsibility to the administrative staff:

"I need them to know my expectations and my needs to run the clinic smoothly" (AA5)

Administrative assistants also emphasized the importance of personal organization skills that were necessary for smooth operations of the practice:

"They are pulled in a lot of directions and [must] keep track of themselves, their patients and organizing with us. More communication at the beginning assists everyone and then they're not missing a clinic" (AA3)

and the importance of "check-ins":

"my resident forgot his/her clinic last time and it was a full clinic. Now he/she checks-in with me more often and there are no issues" (AA8)

Administrative activities, such as scheduling, also supported professional development. They ensured that the clinic load was distributed to allow the residents' time to review. Once residents gained proficiency, the administrative assistants increased the patient load:

"at the beginning, they only see a couple of patients in each clinic and as they progress, they can see more people. At first, they don't want to miss anything [and] are extremely thorough. As they get used to the new patients, it becomes more natural" (AA2)

They also advised the residents on how to navigate the healthcare setting for organizing tests or consultations for their patients:

"If it's a test that is done only at [another hospital], we get them the right referral papers and faxes"(AA1)

Administrative assistants also provided feedback to the attending physician when residents demonstrated poor organization skills, poor communication or a lack of ownership in responding to patient questions or acting on results of investigations:

"I let the doctor know exactly how I feel the fellow is progressing. If they're just not as committed to having their own clinic; if they've forgotten to say they're going to be on vacation; if a patient has called and wants to talk to the fellow that's been looking after them and they neglect to call them back and the 
patient is calling back a second time or third time, I would pass that along. Or if we say, we'll make arrangements for this test and it's a week later and the test has not been ordered, I would pass that along to my boss" (AA1)

\section{Patients with Multi-Morbidity}

In our setting, patient care tasks also included: decision making with family members; counselling patients with substance abuse on risk-reduction; transitioning patients with end-stage disease to symptom management therapy; and tailoring therapeutic recommendations to patients' social situations. These patient care tasks supported PIF by:

- Identifying medical issues that needed attention, but also prioritizing issues: when I see a patient with six issues, I've learned to categorize them. I never used to do that because [in other clinics] it's one system and one problem. [By] categorizing their issues [into] what is active, I learned to manage time and I've learned how to explain their multi-morbid conditions (Graduate5).

- Developing strategies to tackle socio-cultural barriers to optimize care: you have to go beyond the medical and think of the social aspect. Some can't afford medications. Some have come here as refugees. They have all kinds of challenges. The continuity clinic taught me how to tackle these challenges (Resident1).

- Negotiating and setting expectations with patients: you can't address everything in one visit, so sometimes you have to negotiate and set expectations with patients (Resident3).

- Recognizing the "big-picture" of continuity care: as I get more comfortable with managing the medical issues, it is now the bigger picture that I'm focusing on with my patients (Resident2).

- Applying counselling skills: in this setting, you're diagnosing and doing the tests; you have to explain the rationale, the risks, benefits, and side effects of medication, so the whole patient counselling aspect is a skill that I have learned (Resident4).

\section{Relationship Between PIF and GIM Competencies}

As mentioned, we also analyzed the data for the GIM competencies as outlined in the formal curriculum. Specifically, this part of the analysis focused on how the following competencies related to PIF: caring for multi-morbid patients, investigating for undifferentiated multi-system symptoms, managing a GIM practice and developing life-long learning skills. The study demonstrated that PIF starts as early as PGY-4 and competency acquisition occurred simultaneously with PIF.

As experience in GIM evolved, residents became more overt about their management choices:

"the longitudinal clinic made me see the effects of my management. So now I have my own preferred drugs"(Graduate3).

However, the longitudinal experience also highlighted the limitations of GIM expertise and how one had to deal with uncertainty: 
"sometimes there is no answer [in the guidelines]. Then it is your opinion and you have to do what is safe and not necessarily what guidelines suggest" (Resident3).

The most common referral question to a general internist is a set of undifferentiated symptoms. As a result, residents recognized the importance of incorporating life-long learning habits:

"you have to get used to seeing things on the go and constantly learning"(Graduate1).

Residents also noted how their communication style shifts from a learner level to a consultant level: "communicating with other doctors on a shared patient is definitely a big step towards consultancy level" (Graduate1).

Lastly, these collective experiences allowed them to appreciate the "big picture of running a GIM practice" (Graduate2) and develop the skills required to work with administrative staff effectively.

\section{Invisible Learning Experiences}

This study also explored residents' values and perceptions around patient ownership as part of their PIF. The findings demonstrated that, from the residents' perspective, patient ownership is not solely centered on clinical tasks, such as, follow-up of investigations or responding to questions by the patient. As their patient ownership and experience evolved, residents adopted values about patient care through the assumptions they made about the expectations of a GIM practice. Hence, these assumptions were not explicitly discussed with supervisors. We refer to these findings as invisible learning experiences.

We identified four prevalent themes around the invisible learning experiences: emotional investment, perseveration, extreme ownership, and rationalization. Residents consistently reported these experiences starting in PGY-5, when they had been granted more independence by the attending physicians. While there was variability, across residents, in the nature of the invisible learning, each experience represented a trajectory in their PIF. All residents felt that these were crucial for patient ownership and part of being an internist. At times, the invisible learning blurred the lines between therapeutic patient ownership and potentially dysfunctional ownership.

We explored how residents' approach to patients with multi-morbidity had changed. One resident described how interacting with patients and their families had started to drain them emotionally when discussing critical illnesses: "when I get a call about something that's gone wrong with a patient, or I get back results that are grave for them, I didn't find it emotionally draining before because I didn't know the patients well, you didn't know their families, their stories. But when you know them for a year-and-a-half, it's emotional (Resident2).

We also explored the ways in which residents felt that they were taking on increasing patient ownership. One resident described their practice with a multi-morbid patient: "I have been following la complex patient] since my third year. He has blood work every four weeks. I see him every six weeks. I find myself 
checking up on him every two weeks, which I never would have done with any patient before because he sees me as his physician over my supervisor" (Resident1).

While all residents were able to acknowledge that medical complications were a natural course of multimorbid illnesses, they personally struggled to deal with these complications or concurrent illnesses affecting their patients: "I get really upset when my patients get admitted to hospital, even if it's for something unrelated. It's hard not to blame yourself with the complex patients, [even if] it's just the nature of the disease [or] even if you've managed all of their other comorbidities. They're mine, and I care about them. I think to myself did I miss something" (Resident3).

In other instances, residents felt the need to rationalize their extent of ownership: "My complex patients rely on me in a way that I wasn't prepared for. When I explain that I look after certain conditions, they can get inappropriate and it is my responsibility for everyone's safety. I tell myself that this is the disease and they wouldn't be like this if they didn't have these illnesses" (Resident5).

We probed these findings in our interviews with the attending physicians to understand their observations. The participants attributed the findings to three key factors:

- Role of an internist: resident $X$ feels she/he needs to do this to be a good physician (AP4)

- Acceptable levels of clinical uncertainty: this is normal clinical uncertainty that evolves with time (AP1)

- Stress of certification exams during training: they are stressed out about the exams; it is not the patients in clinic (AP2 and AP3).

\section{Discussion}

We observed that PIF and acquisition of specialty-specific competencies is a co-dependent and dynamic process in advanced residents, such that residents developed in unique and sometimes unexpected ways. Thus, we perceived the process as an ebb and flow during development, rather than linear or unidirectional. Our findings further elaborate on the PIF and socialization scheme proposed by Cruess and colleagues [14], by suggesting that placing too much emphasis on competency acquisition or on professionalism traits that are critical to the specialty, can lead to adoption of beliefs and values that are counter-productive to functioning as a physician. In addition to this, our findings demonstrate the unintended consequences of staged granting of independence as a resident's professional identity evolves. Our study also demonstrates how supervisors and patients, in continuity care settings, shape the PIF process and support competency acquisition. This is also the first study to identify the role of administrative assistants in PIF. Lastly, the study identifies an unexpected finding of PIF that we refer to as invisible learning experiences, in which residents made assumptions about expectations of patient ownership.

Across participants, there was a range of supervisory support, provided by the attending physician, as well as scaling back of support once residents developed greater independence and confidence in their 
role. Each type of support facilitated the acquisition of specialty-specific competencies and the development of professional attitudes that were key in providing care to the multi-morbid population on a continuum. Thus, our findings explicitly demonstrate when mentorship, coaching, and modelling were conducive to PIF and competency acquisition in the care of multi-morbid patients. Similarly, others have described the process of modifying supervisory practices based on competing clinical priorities [34] and on patient care needs [35]. However, our findings speak to the supervisory needs of advanced trainees, who are being prepared to take on a multi-faceted patient ownership role for complex patients. In this context, our findings demonstrate the relationship between supervision and PIF.

An additional important element of this study is the key role of administrative assistants in PIF and the overarching goal of learning practice management. While this requires further investigation, it is a prominent theme in our findings. Administrative assistants acted as an integral part of learning by providing feedback; scaffolding trainees alongside the supervisors and helping residents recognize how to run an effective GIM practice. Thus, drawing boundaries of what constitutes professional practice is critical for PIF in the continuity clinic.

As pointed out in the PIF and socialization literature [ $3,14,15,17]$, our study findings are consistent in how an interaction with patients and their caregivers facilitates PIF. However, all of the identified invisible learning experiences were in the context of longstanding patient relationships, a finding that is not explained by the existing PIF scheme [14]. These findings may also represent the hidden curriculum [36, 37] of the GIM continuity training, as participants report that they learned this from the clinical experience rather than the program's formal teaching and that they felt it was important in being an internist. In light of this, we strongly feel that continuity training models must make space for residents' invisible experiences and implement strategies for structured reflection, even at a stage when full independence has been granted.

Granting independence is the eventual goal of any supervisory experience in medicine. In our study we observed how attending physicians accomplished this in stages between PGY-4 to the end of PGY-5. As a result, we were also able to observe how the relationship between attending physicians and residents transitioned from apprentice to colleague over time. However, we were concerned with the unintended consequences arising during this transition: residents' invisible learning experiences. Upon probing these experiences further with the attending physicians, we observed that their primary focus was enabling professional values, such as, a sophisticated level of communication, greater patient ownership, independent clinical decision-making, and strategic use of resources. Creuss and colleagues have emphasized that trainees cannot fully grasp the full breadth of experiences of practicing physicians because they are not developmentally advanced [14]. Hence, this points to the need for balancing the push for ownership and competency acquisition with the need for structured reflection of residents' experiences.

Our study has its limitations. This was a single center study of a new training program launched in 2012 . As a result, we had only a small number of participants. To protect participants' privacy, we were unable 
to disclose the clinical contexts of the residents' invisible learning experiences. Hence, this limited a full exploration of these experiences with the attending physicians. Despite these limitations, some of the findings may resonate with other sub-specialty programs where residents provide care to patients with multi-morbidity in continuity settings.

\section{Conclusions}

The formation of professional identify does not end upon training completion. Theoretically, PIF continues with each new professional challenge $[13,19]$. Although more research is needed, we postulate that the invisible learning experiences will decrease with time, while other values may emerge, around managing administration challenges and adjusting to new patient care demands. While we highlighted three key elements in this discussion, it is important to acknowledge that the process is much more complex. It represents an ebb and flow in identity formation, rather than a continuous unidirectional path. Future studies should explore how independent professional practice further transforms a physician's professional identity and how sub-specialty training programs can balance granting of independence with supporting the evolving professional identity.

\section{Abbreviations}

PIF

Professional Identity Formation

CBME

Competency Based Medical Education

GIM

General Internal Medicine

PGY

Post graduate year

\section{Declarations}

\section{Ethics approval and Consent to Participate}

Ethics approval was obtained from the Western University and London Health Sciences Research Ethics Board (Reference:108085). Written consent was obtained from all participants for audio recording and for use of anonymized transcripts.

\section{Consent for publication}

Not Applicable

\section{Availability of Data and Materials}


The datasets used and analysed during this study are available from the corresponding author on reasonable request

\section{Competing Interests}

The authors declare that they have no competing interests

\section{Funding}

This study was funded by The Department of Medicine, Western University.

The Department of Medicine was not involved in the design of the study and collection, analysis, and interpretation of data and in writing the manuscript.

\section{Authors Contributions}

$\mathrm{NH}$ designed the study protocol, developed the preliminary codes, analysed the data and wrote the manuscript. SC developed the study methodology and supported the code refinement and iterative data analysis phases. SC also contributed to the manuscript. LF trained two of the research team members (EL and MS). LF informed the study concepts and the study methodology. LF also supported the refinement of the codes and iterative data collection. EL and MS collected and analysed the resident and graduate participants' data. RP and CW collected and analysed the administrative assistant and physician supervisor participants' data. All authors contributed to the review of the manuscript and have approved this manuscript for submission.

\section{Acknowledgements}

Not Applicable

\section{References}

1. Weaver R, Peters K, Koch J, Wilson I. "Part of the team": Professional identity and social exclusivity in medical students. Med Educ. 2011;45(12):1220-9.

2. Wong A, Trollope-Kumar K. Reflections. An inquiry into medical students' professional identity formation. Med Educ. 2014;48(5):489-501.

3. Adema M, Dolmans DHJM, Raat J, Scheele F, Jaarsma D, Helmich E. Social Interactions of Clerks. Acad Med. 2019;1.

4. Hendelman W, Byszewski A. Formation of medical student professional identity: categorizing lapses of professionalism, and the learning environment. BMC Medical Educ. 2014;1-10.

5. Sharpless J, Baldwin N, Cook R, Kofman A, Morley-Fletcher A, Slotkin R, et al. The Becoming Acad Med. 2015;90(6):713-7. 
6. Boudreau JD, Macdonald ME, Steinert Y. Affirming professional identities through an apprenticeship: Insights from a four-year longitudinal case study. Acad Med. 2014;89(7):1038-45.

7. Stubbing E, Helmich E, Cleland J. Authoring the identity of learner before doctor in the figured world of medical school. Perspect Med Educ. 2018;40-6.

8. Joseph K, Bader K, Wilson S, Walker M, Stephens M, Varpio L. Unmasking identity dissonance: exploring medical students ' professional identity formation through mask making. Perspect Med Educ. 2017;99-107.

9. Clandinin DJ, Cave MT. Creating pedagogical spaces for developing doctor professional identity. Med Educ. 2008;42(8):765-70.

10. Sawatsky AP, Nordhues HC, Merry SP, Bashir MU, Hafferty FW. Transformative Learning and Professional Identity Formation During International Health Electives. Acad Med. 2018;93(9):138190.

11. Rodríguez C, Pawlikowska T, Schweyer F, López-roig S, Bélanger E, Burns J, et al. Family physicians ' professional identity formation: a study protocol to explore impression management processes in institutional academic contexts. BMC Medical Educ. 2014;1-11.

12. Jauregui J, O'Sullivan P, Kalishman S, Nishimura H, Robins L. Remooring: A Qualitative Focus Group Exploration of How Educators Maintain Identity in a Sea of Competing Demands. Acad Med. 2019;94(1):122-8.

13. Chow CJ, Byington CL, Olson LM, Ramirez KPG, Zeng S, López AM. A conceptual model for understanding academic physicians' performances of identity: Findings from the university of Utah. Acad Med. 2018;93(10):1539-49.

14. Cruess RL, Cruess SR, Boudreau JD, Snell L, Steinert Y. A schematic representation of the professional identity formation and socialization of medical students and residents: A guide for medical educators. Acad Med. 2015;90(6):718-25.

15. Cruess RL, Cruess SR, Boudreau JD, Snell L, Steinert Y. Reframing medical education to support professional identity formation. Acad Med. 2014;89(11):1446-51.

16. Wald HS, Anthony D, Hutchinson TA, Liben S, Smilovitch M, Donato AA. Professional Identity Formation in Medical Education for Humanistic, Resilient Physicians. Acad Med. 2015;90(6):753-60.

17. Cruess RL, Cruess SR, Steinert Y. Medicine as a Community of Practice: Implications for Medical Education. Acad Med. 2018;93(2):185-91.

18. Wald HS. Professional Identity (Trans)Formation in Medical Education. Acad Med. 2015;90(6):7016.

19. Reis SP, Wald HS. Contemplating Medicine During the Third Reich. Acad Med. 2015;90(6):770-3.

20. Cope A, Bezemer J, Mavroveli S, Kneebone R. What Attitudes and Values Are Incorporated into Self as Part of Professional Identity Construction When Becoming a Surgeon? Acad Med. 2017;92(4):544-9. 
21. Rosenblum ND, Kluijtmans M, ten Cate O. Professional Identity Formation and the ClinicianScientist. Acad Med. 2016;91(12):1612-7.

22. Sundberg K, Josephson A, Reeves S, Nordquist J. May I see your ID, please ? An explorative study of the professional identity of undergraduate medical education leaders. BMC Medical Educ. 2017;1-8.

23. ten Cate 0 , Scheele F. Competency-based postgraduate training: can we bridge the gap between theory and clinical practice? Acad Med. 2007;82(6):542-7.

24. ten Cate 0 . Entrustability of professional activities and competency-based training. Med Educ. 2005;39(12):1176-7.

25. Frank JR, Snell LS, Cate O, Ten, Holmboe ES, Carraccio C, Swing SR, et al. Competency-based medical education: theory to practice. Med Teach. 2010 Jan;32(8):638-45.

26. Jarvis-Selinger S, Pratt DD, Regehr G. Competency Is Not Enough. Acad Med. 2012;87(9):1185-90.

27. Tagawa M. Scales to evaluate developmental stage and professional identity formation in medical students, residents, and experienced doctors. BMC Medical Educ. 2020;1-9.

28. Lewin LO, McManamon A, Stein MTO, Chen DT. Minding the Form That Transforms. Acad Med. 2019;1.

29. Cruess RL, Cruess SR, Steinert Y. Amending Miller's Pyramid to Include Professional Identity Formation. Acad Med. 2016;91(2):180-5.

30. Schrewe B, Bates J, Pratt D, Ruitenberg CW, McKellin WH. The Big D(eal): professional identity through discursive constructions of "patient.". Med Educ. 2017;51(6):656-68.

31. Hesse-biber SN, Charmaz K. Grounded Theory as an Emergent Method. In: Hesse-Biber S, Leavy P, editors. Handbook of Emergent Methods. New York London: The Guilford Press; 2008. pp. 155-70.

32. Watling CJ, Lingard L. Grounded theory in medical education research: AMEE Guide No. 70. Med Teach. 2012;34(10):850-61.

33. Royal College of Physicians and Surgeons of Canada. Objectives of Training in the Subspecialty of General Internal Medicine. 2012.

34. Goldszmidt M, Faden L, Dornan T, van Merriënboer J, Bordage G, Lingard L. Attending Physician Variability Acad Med. 2015;90(11):1541-46.

35. Kennedy TJT, Lingard L, Baker GR, Kitchen L, Regehr G. Clinical oversight: conceptualizing the relationship between supervision and safety. J Gen Intern Med. 2007 Aug;22(8):1080-5.

36. Hafferty FW. Beyond curriculum reform. Confronting medicine's hidden curriculum. Academic Med. 1998;73(4):403-7.

37. Ozolins I, Hall H, Peterson R. The student voice: recognizing the hidden and informal curriculum in medicine. Med Teach. 2008;30(6):606-11. 